Irish Math. Soc. Bulletin

Number 88, Winter 2021, 5-13

ISSN 0791-5578

\title{
Lawrence J. Crane (1931-2021)
}

\author{
JOHN J. H. MILLER (COMPILER)
}

\section{Brief Overview}

Lawrence John Crane, who died in March 2021, aged 89, was one of the leading applied mathematicians of his day in Ireland. His lifelong enthusiasm for the subject was appreciated by his students and colleagues in Trinity College, where he lectured for over forty years.

Born on 11 July 1931 in Neilston, near Glasgow, the youngest of four, he graduated from Glasgow University in 1954 with a BSc in Mathematics and Natural Philosophy. As a Mathematics student, his skills found applications in the Torpedo Experimental Establishment in Greenock, near Glasgow.

He went to Dublin for the first time in 1954-55 as a scholar at the school of Cosmic Physics in the Dublin Institute of Advanced Studies. In 1955 he was awarded the James Caird scholarship in Aeronautics at the University of Strathclyde. From 195761 he lectured in Applied Mathematics in Strathclyde and completed his Ph.D. on 'Properties of Jets and Wakes' under the supervision of Prof Donald Pack. In 1959 he spent a year in Germany as a scholar in Freiburg supervised by Prof. Henry Görtler. He was awarded a D.Sc in 1976 and the William Jack Prize in 1977 for his research, both from Glasgow University .

He moved to Dublin in 1961 and joined the TCD School of Mathematics, where he worked until his retirement in 2001. Students - especially in engineering - appreciated his ability to make complex material tractable. He applied his mathematics skills to solve real world problems in engineering, physics and pharmacy. In his early years in Trinity he conducted USAF-sponsored research with Percy McCormack on the break-up of liquid jets.

He started a successful Erasmus programme in Trinity in the 1980s in conjunction with TU Darmstadt, Germany where he was a visiting professor in 1985. Laterally, Lawrence continued to work on boundary layer and slip flow problems. He continued to contribute in a meaningful way to advances in the field of fluid dynamics. This commitment continued into his 80 s with ongoing collaborations on wave energy research and the supervision of students. He published his last paper in 2017 and made notable advances in research up to a few weeks before his death.

He was a master at transforming a complex problem to the most simple, elegant form, while preserving its essential features. His favourite maxim "the best is the enemy of the good" was shown by his ability to find a close approximation to almost any problem, in his head. Notably, he discovered one of the few exact solutions of the Navier-Stokes equations. His professional approach to applied mathematics and his published works are highly regarded by his peers.

2020 Mathematics Subject Classification. 01A70; 76-00, 80-00.

Key words and phrases. Lawrence Crane, obituary.

Received on 7-11-2021, revised 10-11-2021.

DOI:10.33232/BIMS.0088.5.13. 


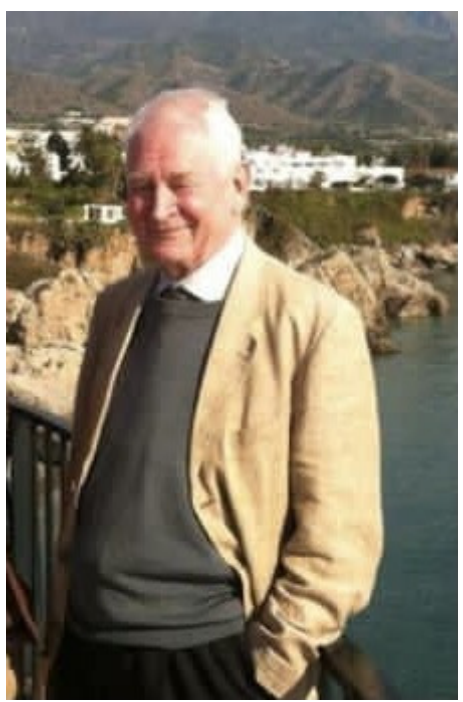

On holiday in Spain

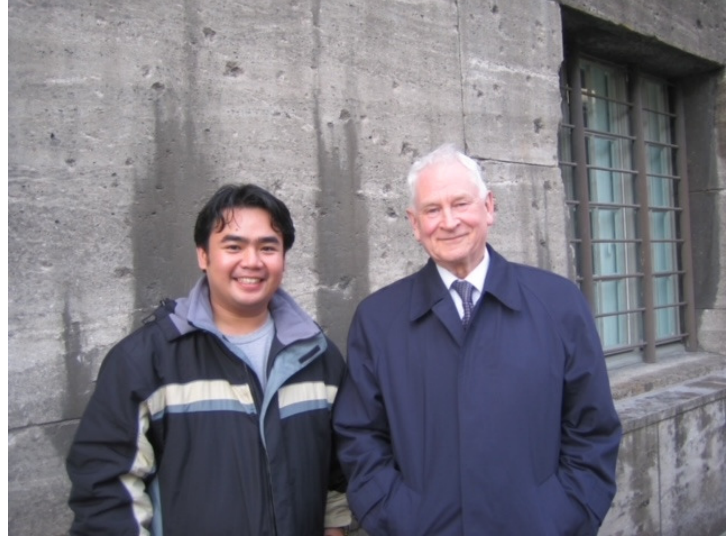

With INCA student Nopparat Pochai

Since his twenties Lawrence enjoyed travelling. Germany was a favourite and frequentlyvisited destination with many business trips and numerous holidays there. In 2010 he completed the final section of the Camino de Santiago on his own. He enjoyed attending and contributing to international mathematics conferences. He was an avid reader on a wide range of topics including military history, scripture, history of mathematics and science. All his life he was a regular churchgoer with deeply held beliefs. He was very interested in theology and scripture and his faith gave him solace in his final months.

He was generous with his time and always willing to help other people, tutoring disadvantaged students in mathematics and statistics for the Ballymun JUST Programme and delivering 'meals on wheels' for many years in Clontarf. He connected easily with people from all walks of life. He had a friendly and engaging personality and frequently struck up conversations with people anywhere - often in different languages! His great enthusiasm for life made him an eternal optimist. He was a very modest man who wore his achievements lightly and placed high value on family and friendship.

He was predeceased by his wife Mary and is survived by his children Stephen, Martin and Alison and his four grandchildren.

May he rest in peace.

\section{Some BRIEF REMiniscences By COLLEAGUes}

Lawrence is fondly remembered as an inspiring, influential Adviser whose warm and generous nature made him a pleasure to work with. Forever meticulous in style and methods, he always radiated enthusiasm for his work and had a natural ability to provide deep insights into approaches to many technical problems. Clearly, Lawrence loved mathematics ("it's great fun!") and constantly stirred thought and enquiry always striving to extract solutions in their most elegant form. Following his final doctoral supervision duties with INCA, Lawrence continued to work on boundary layer and slip flow problems. Throughout the past decade, the quality and quantity of his research never flagged and, up to 2016, he continued to collaborate and contribute to advance the field of fluid dynamics. Up to recent years, Lawrence continued to enjoy international travel - especially to mathematics conferences. One of his most memorable occasions was accepting an invitation to attend a mathematics ceremony in the Royal Society, London. Typically in such events, Lawrence actively engaged with attendees and was always eager to participate in discussions on historic and technical matters. In all locations visited, Lawrence would acquaint himself with the historic backdrops and 
seek out buildings and architecture of interest. Of course, no trip would be complete without a visit to an old bookstore or two and occasionally, to some unassuming local restaurant! He will be deeply missed by all students and researchers who had the honour of knowing and working with him. Tony McVeigh.

I will let others talk about his work in academia, and his expertise in Fluid Mechanics. What I noticed a number of times was his genuine affection for some of his former PhD students. Some of them he kept in touch with, and some even came to visit him in Ireland.

In his later years, he became very interested in family history. We worked on this together. He was quite happy for me to work the PC, while he did the thinking. In this area, he showed amazing creativity, flexibility, and a genuine delight when we established another good connection with his past. By far his most endearing trait in this area was his dogged determination to follow all the leads until he was satisfied that we had tied down a cast iron conclusion.

He was a born optimist and if you happened to meet him on a bad weather day, you had better be ready with a positive response, or you were not at the races! Diarmuid Herlihy.

When I think back over the time for which I have known Lawrence - almost sixty years, dating from my arrival in Trinity as an undergraduate, which coincided with his as a lecturer - I find that the last ten years or so have provided some of the most distinctive memories. We came together naturally at events such as the School of Mathematics Christmas lunch: recalling past times and former students, or simply chatting as friends. We also met with past classmates of mine when they were back in Trinity for the Scholars' Dinner in 2014, and enjoyed a very happy afternoon tea and chat in the Davenport Hotel. Thus, the picture of Lawrence that first comes to mind now is of a friend among a circle of friends, enjoying good food and equally good conversation.

Of course there are more academic memories also. Lawrence lectured me in mechanics and fluid dynamics. I think of him often when I am flying (or when I was flying, in the days when air travel was normal), with reference to the fluid dynamics; the flow round aerofoils, in this case aeroplane wings, is keeping the plane in the air. He contributed also to the world of school mathematics, for instance through his role in cooperating on the selection of a teacher of Applied Mathematics to receive the Victor Graham trophy, presented annually. While Lawrences family and his research colleagues will miss him most, all his friends and colleagues regret the loss of his friendly and calm presence. Elizabeth Oldham.

Lawrence and I worked together in INCA for more than 20 years, after we had both retired from TCD, in 2001 and 2000 respectively. It was a happy period for us both; we were delighted to be in a stable, secure environment that we controlled. The only pressure on us was the self-imposed drive to design and construct a technically and commercially feasible device to harvest the power of ocean waves for the generation of electricity. The device we chose was a Masuda buoy, a floating axi-symmetric buoy containing an oscillating water column. This apparently simple task had not been completed in 2001, and this is still the case 20 years later. Personally, our pensions gave us financial security and, academically, we had done our best in teaching and research during our years in TCD. We were now free and we let the technical demands of the daily tasks determine our actions. We were able to spend the time necessary to deal with each technical question as it arose and we had no need to spend time seeking extra funding. Pencils, paper, a pocket calculator, a desktop computer and knowhow were all that we needed. From time to time colleagues in the same field made 
interesting observations about our work: one young colleague said that all we were doing was schoolboy mathematics, although later the boss said that he wished he had been aware of our work before he built his own device. On another occasion Lawrence was working quietly in the visitors' room at a wave tank facility. A senior technician was making a phonecall to his boss from an adjoining room separated by a partition that did not quite reach the ceiling. Thinking that he was talking privately he was heard to say that "the two chaps from Dublin were getting on with their testing and although they were rather old, they seemed to know what they were doing". We took this as one of the best compliments we had ever received! It is a pleasure to have worked with Lawrence over such a long period and we had great fun. John Miller.

In his lectures, Lawrence had a particular skill in teaching an understanding of differential equations, their solution and their application to real-life problems, whether in an introductory 'methods course or a more advanced course on fluid dynamics. He found TCD an extremely friendly environment. In conversation, a few weeks before he died, he told me that he considered the university had high standards in mathematics, and higher expectations of students than was the norm elsewhere. At that time, women were excluded from senior academic positions at the university (including Fellowship); moreover, they were obliged to have left the campus by 6 p.m.! He admired how the mathematics students were devoted to running their own activities in the Dublin University Mathematical Society (DUMS), and took great care in preparing their meetings. He had a strong interest in the history of mathematics, and especially in the contributions of Scottish and Irish mathematicians. He was shocked to learn that, fairly recently, students in the DUMS had decided to dump their library (including the Fry and Rowe collections) in a skip. Maurice O'Reilly.

Lawrence's research interest throughout his career was Fluid Mechanics, an important subject in which he had several research students. By all accounts Lawrence was an excellent and caring lecturer. Apart from the lectures on his favourite Fluid Mechanics, he lectured on Mathematical Methods and shared a lecture course with me on Dynamics for the engineering department. Engineering graduates of the 1970s and 1980s, who themselves reached enviable heights in their subsequent research, still speak most highly of the Dynamics lectures and how inspiring and essential they are in their work. Lawrence played his part in the life of the mathematics department and of the College, in general. Mention must be made of the highly successful Erasmus Program between Trinity College and the University of Darmstadt; it was all due to Lawrences hard work. He was a wonderful colleague and friend in every way. He will long be remembered with great fondness and admiration. Petros Florides.

I have known Lawrence for over 50 years; he was already in the Department when I came in 1966. He was a welcoming and helpful presence to me then, and through the years continued to be a much valued and supportive colleague. I have always held him in high regard. Whenever I needed help, for example, as sometimes happened, to fill in on a course, I knew that I could turn to him; he would always, willingly, and unhesitatingly, step in even at short notice. Lawrence was a very good teacher; he was responsive to the needs of his students, and they benefited from and appreciated his courses. He was always accessible to any colleague, not only from Mathematics but also from Engineering and from other departments, who came to him with a mathematical or technical problem; he would either help them to solve their problem directly, or if it were more involved would engage with it and sometimes collaborate in resolving it. He was a seriously professional mathematician with a deep commitment to his subject, which was sensed by his students, and which added to the credibility of his lectures. This commitment and engagement continued after his retirement, in particular through 
an ongoing collaboration in INCA which was a serious interest and source of satisfaction and fulfilment for him. David Spearman.

Lawrence gave magnificent courses in mechanics and the partial differential equations of mathematical physics which have been a source of inspiration through my professional life. I always found him to be very kind in all my dealings with him likewise with other students. My only regret is not being able to attend his course on Fluid Mechanics which was not part of the Engineering degree at the time. He had the very valuable knack of rendering the most difficult of subjects rather simple. I consider it a great privilege to have known him as a person and as an applied mathematican who engendered an abiding interest in his subject. William Coffey.

\section{Academic Career}

\section{Studies, Qualifications and Awards}

1950-54 Student in Glasgow University.

1954 B.Sc. (First Class Honours) in Mathematics and Natural Philosophy.

1954-55 Scholar, Dublin Institute of Advanced Studies, School of Cosmic Physics.

1955-57 Sir James Caird Scholar in Aeronautics at the University of Strathclyde, Glasgow.

1957-58 Assistant Lecturer in Mathematics, University of Strathclyde, Glasgow.

1958-61 Lecturer in Mathematics, University of Strathclyde, Glasgow.

1959 Scholar, Deutsche Versuchsanstalt für Luftfahrt, Freiburg, West Germany.

1960 Ph.D, Glasgow University.

1961 Lecturer in Applied Mathematics, Trinity College, Dublin.

1976 D.Sc, Glasgow University.

1977 Awarded William Jack Prize in Mathematics by Glasgow University.

\section{Research Experience}

1957-58 Research (leading to the degree of Ph.D) in viscous jets and wakes under the supervision of Professor D.C. Pack, at the University of Strathclyde.

1959 Research in secondary flows under Professor H. Görtler, D.V.L. Institute, Freiburg. 1962-65 Research in collaboration with P.D. McCormack on the break-up of liquid jets; this work was sponsored by the U.S.A.F.

1966-69 Research Consultant with I.C.I. Fibres Ltd., Harrowgate, Yorkshire. Research was carried out on fluid flow and heat transfer on spinning fibres.

1973-77 Research contract with U.K. Atomic Energy Authority on Entry and Exit flows in Nuclear Reactors.

1981 DAAD supported research project on Rotating flows.

1989-93 Research contract with AKZO-NOBEL, Klingenberg, Bavaria on air flow in fibre bundles.

1998-99 Research project for Siemens A.G. Mülheim, Germany on deposition of particles on turbine blades.

1993-97 Brite Euram SISCO project on detection of cracks in thin plates by RayleighLamb waves.

1998 onwards. Research Consultant with Freudenberg, KG, Weinheim, Germany, topic: the self suction fibre spinning process.

2000 onwards. Participant in EU Fourth framework PSUDO project on parallel simulation of drug release, then continuing in collaboration with the School of Computer Applications D.C.U. and with the Department of Pharmacy T.C.D.

2003 Sustainable Energy Ireland supported project on air flow past slender towers, in association with Airtricity Ireland. 
Consultant over a period of years to Performance Fluid Dynamics Ltd., Dublin on various fluid dynamical projects.

\section{Academic and other positions}

1965-70 Tutor, TCD

1969 Elected Fellow, TCD

1995 Elected Senior Fellow and Member of Board, TCD

1980 Elected Member of G.A.M.M., (Gesellschaft für Angewandte Mathematik und Mechanik, Germany).

1980 Member of INCA

2000- Treasurer of INCA

\section{Ph.D theses supervised}

B. Siddappa, (1971) Newtonian flows in viscoelasticity.

L.C. Tan, (1977) Pressure Losses in Ducts, Bifurcations and Manifolds.

P. Carragher, (1978) Heat Transfer on continuous solid surfaces.

P. Lynch, (1982) Planetary Scale Hydrodynamic Instability.

B. Redmond, (1994) Drag and Heat Transfer in Melt Spinning.

John Harding, (2007) Incompressible and Compressible Boundary Layers on a Fibre in the Melt Spinning Process, jointly with Dr. Brendan Redmond.

Sandra Spillane, (2008) A Study of Boundary Layer Flow with no-slip and slip Boundary Conditions, jointly with Dr. Brendan Redmond.

A. G. McVeigh (2011) Interactions between Fluid Flow and Cylinders.

David McDonnell, (2012) An Analysis of Drug Dissolution in vivo, jointly with Dr. Brendan Redmond.

\section{M.Sc theses supervised}

S. Siddappa, (1972) Boundary Layer on cylinders.

N.Bach, (1994) Air Flow in fibre bundles.

E. Kenny, (1994) A moving boundary finite element solution of a pharmaceutical drug delivery problem.

C. Schafer, (1995) Finite Difference Approach to Boundary Layer Phenomena.

M. Brennan, (1996) Numerical Study of riblets on drag.

K. Mayes, (1997) Paper motion in printing machines.

P. Cooke, (1997) Steady Laminar Flow in narrow annuli.

\section{Mathematical Career following Retirement from TCD}

During the more than twenty years that followed his retirement from Trinity College, Lawrence remained an enthusiastic and productive research mathematician. During this time he based himself in INCA, the Institute for Numerical Computation and Analysis in Dublin. Founded in 1980, this is an independent non-profit research body, which has official charitable status; it has no paid employees. In the early years of this period Lawrence was one of the two INCA researchers appointed by the Royal College of Surgeons in Ireland as Research Fellows. These were two-year positions without pay.

He was also involved on behalf of INCA in the research training of postgraduate students from Ireland and abroad, notably as the $\mathrm{PhD}$ thesis advisor of a mature student who was awarded a doctorate by the University of Buckingham.

Around 2010 INCA became seriously interested in renewable energy. It was decided that an appropriate approach would be to support the creation of a commercial company, Waveforce Energy Limited, to develop new devices to harvest electric power from ocean waves. It quickly became evident that this was an area in which mathematical and computational modelling could be of great help. As a result, a period of intense 
activity followed, which involved the modelling of the motion of floating oscillating water column buoys in a wide range of ocean conditions from benign wave tanks to the extreme conditions off the west coast of Ireland. In his final years he began work on models of turbines, which he continued to work on until a few weeks of the end. He particularly enjoyed his visits to the wave tanks in Cork, Galway and Glasgow, to JFC in Tuam where the first Waveforce buoys were manufactured and to the ocean test site off Belmullet.

\section{List of Publications}

Below is a list of publications compiled mainly by Lawrence himself in about 2000 around the time of his retirement from Trinity College. Later papers have been added. ZAMM stands for Zeitschrift für Angewandte Mathematik und Mechanik. ZAMP stands for Zeitschrift für Angewandte Mathematik und Physik.

\section{(A) Jets and wakes}

A1 L.J. Crane, D.C. Pack. The laminar and turbulent mixing of jets of compressible fluid. Part 1. Flow far from the orifice. Journal of Fluid Mechanics 2, p.449, 1957.

A2 L.J. Crane, The laminar and turbulent mixing of jets of compressible fluid. Part 11. The mixing of two semi-infinite streams. Journal of Fluid Mechanics 3, p. 81, 1957.

A3 L.J. Crane, D.C. Pack. The mixing of a jet gas with an atmosphere of a different gas at large distances from the orifice. Part 1, The Plane Jet. Quarterly Journal of Mechanics and Applied Mechanics and Applied Mathematics, 14, p.385, 1961.

A4 L.J. Crane, The mixing of a jet gas with an atmosphere of a different gas at large distances from the orifice. Part 11. The round jet. Quarterly Journal of Mechanics and Applied Mathematics, 14, p. 393, 1961.

A5 L.J. Crane, A note on Stewartsons paper "On asymptotic expansions in the theory of boundary layers". Journal of Mathematics and Physics 38, p. 172, 1959.

A6 P.D. McCormack, D. Cochran, L. Crane, Periodic vorticity and its effect on jet mixing. Physics of Fluids. 9, p. 1055, 1966.

A7 L.J. Crane, Error estimate for the Schlichting round jet. Z.A.M.M. 54, p. 591, 1974.

\section{(B) The breakup of liquid jets}

B1 L.J. Crane, S. Birch, P.D. McCormack, The effect of mechanical vibration on the break-up of a cylindrical water jet in air, British J. Applied Physics, 15, p. 743, 1964. B2 P.D. McCormack, L.J. Crane, S. Birch, An experimental and theoretical analysis of cylindrical liquid jets subject to vibration. British J. Applied Physics, 16, p. 395, 1965. B3 P.D. McCormack, L.J. Crane, S. Birch, Derivation of jet velocity modulation caused by injector vibration. British J. Applied Physics, 16, p. 1911, 1965.

\section{(C) Properties of continuous boundary layers}

C1 L.J. Crane, Flow past a stretching plate. Z.A.M.P., 21, p.645, 1970.

C2 L.J. Crane, Boundary layer flow on a circular cylinder moving in a fluid at rest. Z.A.M.P., 23, p. 201, 1972.

C3 L.J. Crane, Heat transfer on continuous solid surfaces, Ingenieur - Archive., 43 pp, 203-214, 1974.

C4 L.J. Crane, Boundary layer flow due to a stretching cylinder. Z.A.M.P., 26, p. 619, 1975.

C5 P. Carragher, L.J. Crane, Heat transfer on a continuous stretching sheet. ZAMM 62, p. 564, 1982. 
(D) Plumes

D1 L.J. Crane, Thermal convection from a horizontal wire, Z.A.M.P.,10, p. 453, 1959.

D2 L.J. Crane, Axially symmetric plumes at large Prandtl numbers. Z.A.M.P., 25, p. 365, 1974.

D3 L.J. Crane, Axially symmetric plumes at very small Prandtl numbers. Z.A.M.P., 26, p. $427,1975$.

D4 L.J. Crane, The round plume due to a falling point source of heat. Z.A.M.P., 28, p. $599,1977$.

D5 L.J. Crane, The plane turbulent plume in a magnetic field. Z.A.M.P., 40, 69-77, 1989 .

\section{(E) Natural convection on cylinders}

E1 L.J. Crane, Natural convection from a vertical cylinder at very large Prandtl numbers. Journal of Engineering Mathematics, 10, p.115, 1976.

E2 L.J. Crane, Natural convection from a vertical cylinder at very small Prandtl numbers. Z.A.M.P., 27, p. 61, 1976.

\section{(F) Suction and blowing}

F1 L.J. Crane, Axial flow past a cylinder with suction. Z.A.M.M., 8, p. 567, 1974.

F2 L.J. Crane, Axial flow past a cylinder with uniform injection. Z.A.M.M., 63, 391, 1983.

\section{(G) Drug dissolution}

G1 L.J. Crane, P.B. Deasy, E.M. Kenny, J. J. H. Miller, The numerical solution of a moving boundary problem in two dimensions with applications to drug delivery systems, Modelling in Mechanics, Tom 7 (24) No. 2 (1993) 124-132.

G2 Crane L.J., Deasy P.B., Kenny E.M., Miller J.J.H., Erosion of an infinite cylinder. Z.A.M.M., 6, 633-635, 1994.

G3 M. Crane, N.J. Hurley, L. Crane, A.M. Healy, Simulation of USP drug delivery problem, Simulation Modelling Practice and Theory, 12, 147-158, 2004.

G4 M. Crane, L. Crane, A.M. Healy, O.I. Corrigan, A Pohlhausen Solution for the mass flux from a multi-layered compact drug, Simulation Modelling Practice and Theory, 12, 397-411, 2004.

\section{(H) Boundary layers and slip flow}

H1 L.J. Crane and A.G. McVeigh, Slip Flow on a Microcylinder, Journal of Applied Mathematics and (ZAMP), Vol 61 (2010), pp 579-582, DOI: 10.1007/s00033-009-0019

H2 L.J. Crane and A.G. McVeigh, Heat Transfer on a Microcylinder with Slip, Journal of Applied Mathematics and Physics (ZAMP), Vol 61 (2010), pp 1145-1149, DOI: 10.1007/s00033-010-0076-1

H3 L.J. Crane and A.G. McVeigh, Accelerated Slip Flow past a Cylinder, Journal of Applied Mathematics and Physics (ZAMP), Vol 62 (2010), pp 365-376, DOI: 10.1007/s00033010-0094

H4 L.J. Crane and A.G. McVeigh, Uniform Slip Flow on a Cylinder, Proceedings in Applied Mathematics and Mechanics (PAMM), Vol 10 (2010), pp 477-478, DOI: 10.1002/pamm.201010231

H5 L.J. Crane and A.G. McVeigh, Steady Flow along a Rankine Half-Body, Journal of Applied Mathematics and Mechanics (ZAMM), Vol 91 (2011), 8, pp 681-686, DOI: 10.1002/zamm.201000197

H6 L.J. Crane and A.G. McVeigh, Slip Flow on a Body of Revolution, Acta Mechanica, Vol 224 (2013), 3, pp 619-629, DOI: 10.1007/s00707-012-0786-x 
H7 L.J. Crane and A.G. McVeigh, Heat Transfer on a Cylinder in Accelerated Slip Flow, Archive of Applied Mechanics, Vol 84 (2014), pp 899-912, DOI: 10.1007/s00419014-0839-9

H8 L.J. Crane and A.G. McVeigh, A Mathematical Account of Draught-Induced Disturbances in the Fibre Spinning Process, Journal of Applied Mathematics and Mechanics (ZAMM), Vol 95 (2015), 12, pp 1439 - 1447, DOI: 10/1002/zamm.201400029

H9 L.J. Crane and A.G. McVeigh, Slip flow along an impulsively started cylinder, Archive of Applied Mechanics, Vol 85 (2015), 6, pp 831-836, DOI: 10.1007/s00419-0140994-7

H10 L.J. Crane and A.G. McVeigh, The Derivation of a Goldstein Formula, General Mathematics Notes, Vol 31 (2015), 2, pp 29 - 33, ISSN 2219 - 7184.

\section{(I) Miscellaneous}

I1 Book: Physical Fluid Dynamics, P.D. McCormack, Lawrence Crane, Academic Press 1973.

I2 P. Carragher, L.J. Crane, Radiative heat transfer on a continuous boundary layer, Z.A.M.M., vol 66, issue 3, 185-187, 1986

. I3 L.J. Crane, M.D. Gilchrist, J.J.H. Miller, Analysis of Rayleigh-Lamb wave scattering by a crack in an elastic plate, Computational Mechanics, 19, 533-537, 1997.

I4 Dr L.J. Crane, Dr S. Sen, A note on slowly convergent double series, Z.A.M.M., 72, 308-310, 1992.

I5 Bach, N., Crane L.J, Miller J.J.H, The effect of riblets in stagnation point flow, Z.A.M.M., 75, 377, 1995.

I6 N. Pochai, S. Tangmanee, L. J. Crane, J. J. H. Miller, A Mathematical Model of Water Pollution Control Using the Finite Element Method, PAMM, Vol 6(1): 755-756, Berlin (2006).

I7 N. Pochai, L. J. Crane, J. J. H. Miller, S.Tangmanee, A Numerical Computation of Velocity and Water Elevation in One-dimensional Hydrodynamic Model, Proceedings in the International Conference on Engineering, Applied Sciences, and Technology (ICEAST 2007), King Mongkuts Institute of Technology Ladkabang, Thailand (2007). I8 N. Pochai, S. Tangmanee, L. J. Crane, J. J. H. Miller, A Water Quality Computation in the Uniform Channel, Journal of Interdisciplinary Mathematics Vol.11, 6, 803-814 (2008).

I9 N. Pochai, S. Tangmanee, L. J. Crane, J. J. H. Miller, A Water Quality Computation in the Uniform Reservoir, Journal of Interdisciplinary Mathematics Vol 12, 1, 19-28. (2009)

I10 L. J. Crane, J. J. H. Miller, A simple nonlinear model of a generic axisymmetric wave energy converter, Mathematical Communications 17, 1, 303-312 (2012).

I11 N. Pochai, S. Tangmanee, L. J. Crane, J. J. H. Miller, A Finite Element Simulation of Water Quality Measurement in the Open Reservoir, Thai Journal of Mathematics Vol 7, 2, 293-209 (2009).

http://math.science.cmu.ac.th/thaijournal/

\section{ACKNOWLEDGEMENTS}

John Miller is grateful to the Crane family, especially Alison, for much help in compiling this piece. Thanks are also due to the authors of the reminiscences.

Department Of Mathematics, Trinity College, Dublin, Ireland

E-mail address: jmiller@tcd.ie 